\title{
THE EFFECTS OF PEOPLE- AND TECHNICAL- ORIENTED TQM ON PRODUCTIVITY: THE MEDIATING ROLE OF PRODUCTION PERFORMANCE
}

\author{
Arawati Agus \\ Universiti Kebangsaan Malaysia \\ Rajni Selvaraj* \\ Universiti Kebangsaan Malaysia
}

\begin{abstract}
The purpose this study is to examine the importance of incorporating both technical-oriented and peopleoriented Total Quality Management (TQM) within the context of the Malaysian manufacturing industry with the aim of improving overall productivity within the industry. The study adopts a quantitative approach using Pearson's correlation and Structural Equation Modeling (SEM) to investigate the relationships between technical- and people-oriented TQM, production performance and productivity on a sample of 169 senior production or TQM managers. The results demonstrated substantial evidence whereby technical-oriented TQM dimensions, namely 'benchmarking', 'quality measurement' and 'process improvement' exhibited significant impact on production performance and productivity. Furthermore, people-oriented TQM dimensions, namely 'employee focus', 'customer focus' and 'supplier relations' played a significant role in enhancing productivity. As such, the results of the study suggest that both TQM orientations are crucial for a successful adoption of TQM. The findings of the effect of TQM dimensions on production performance and productivity of Malaysian manufacturing organizations have been encouraging. Future studies should explore determinants of productivity that is in line with the business landscape of specific industries, in order to meet the growing demands of high-quality outputs.
\end{abstract}

Keywords: Total Quality Management (TQM); People-oriented and technical-oriented TQM; Production performance; Productivity and Structural Equation Modeling (SEM).

Received: 22 November 2018

Accepted: 27 July 2019

\section{INTRODUCTION}

In Malaysia, manufacturing sector plays a vital role in contributing to the success of its industrial and economic growth. In Saieed's article (2018), the manufacturing sector has been contributing about $23 \%$ to the country's GDP in the last five years. Further, about $98.5 \%$ of Malaysian SMEs are in the manufacturing sector. Given that Malaysia has lagged behind over the last one and a half decades, the is a call to step up and draw closer to our competitors. In line with the call to build an economy that is competitive, dynamic, robust and resilient, the National Policy on Industry 4.0

\footnotetext{
- Corresponding author: Graduate School of Business, University Kebangsaan Malaysia, Bangi, 43600, Malaysia: zp03060@siswa.ukm.edu.my
} 
known as Industry4WRD was launched, as a strategy to boost Malaysia's manufacturing sector, aimed at increasing productivity by $30 \%$.

With market globalization and economic liberalization, many Malaysian manufacturing companies have started embarking on implementing Total Quality Management (TQM) strategies as a means for business excellence and strategy for improving competitiveness, both domestic or international marketplaces (Sinha, Garg \& Dhall, 2016; Ooi, 2015). Total Quality Management (TQM) is a comprehensive quality management system aimed at improving quality of goods and services delivered through the participation of all levels and functions of the organization (Putri, Mohd Yusof, Hasan \& Darma, 2017; Dubey and Gunasekaran, 2015). Total Quality Management is acknowledged as a total system approach that focuses on enhancing specific performances and productivity within various industries. Successful implementation of TQM has been proven to improve employees' productivity and organizational performance (Putri et al., 2017).

In reality, productivity has become an issue of great concern and addressing this concern has become a priority in the public as well as private sectors in Malaysia. Productivity is considered a significant factor that contributes to the successful operation of an organization in the competitive business arena (Seto-Pamies, 2012). Earlier studies suggested that productivity is likely to be the most crucial area of operations management (Kang, Zhao, Li \& Horst, 2016). Other researchers pointed out that productivity enhancement initiatives are instrumental in driving profitability, cost competitiveness and long-term growth (Song, Zhao \& Zeng, 2017; Neely, Gregory \& Platts, 2005). It is therefore apparent on how significant the implementation of TQM and production strategy is to the manufacturing industry, as it will encourage an organization to consider their economic activities, production efficiency and effectiveness in greater depth. It is noteworthy to mention that a number of studies within this field has increased significantly over the years in developing and emerging countries. Such significance aligns to the need to further explore this study within the Malaysian context. Moreover, TQM can most likely be a significant factor within process and production management (Kang et al., 2016). Despite a variety of evidences confirming that TQM relates to improvement in productivity, very limited empirical evidence to suggest the importance of measuring the extent of productivity or improvements in productivity that have resulted from the TQM programs. In other words, there are very few published studies, especially from the Malaysian context that have investigated the enhancement of productivity and production performance of manufacturing companies as a consequence of TQM implementation strategy. This study endeavours to address the gap by empirically investigating people-oriented and technicaloriented TQM implications on production performance and productivity in the context of Malaysian manufacturing industry.

Within this context, we investigate the relationship between technical-oriented TQM and peopleoriented TQM, and its connection with production performance and productivity. The technicaloriented TQM dimensions are benchmarking, quality measurement and process improvement, whereas the people-oriented TQM dimensions are employee focus, customer focus and supplier relations. Limited studies have investigated the effects of TQM on productivity through the effects of enhancing production performance within the organization (Khademfar \& Amiri, 2013). As such, the need to innovate and find alternative strategies to enhance productivity within the manufacturing industry is justified. Moreover, the basis of selecting TQM is inherent in its philosophy, aimed at continuously improving quality and performance which is vital for maximizing operational capacity in the manufacturing industry (Ilkay \& Aslan, 2012). 
This study has four main objectives: 1) Assessing the effects of each dimension on technicaloriented and people-oriented TQM; 2) Examining the effects of people-oriented TQM on productivity; 3) Examining the effects of technical-oriented TQM on production performance; and 4) Examining the effects of production performance on productivity.

\section{LITERATURE REVIEW}

\subsection{TQM Practices, Production Performance and Productivity}

TQM offers guiding principles that emphasizes on continuous improvement of products and services to meet or possibly exceed the requirements or expectations of the customers organization (Putri et al., 2017; Dubey \& Gunasekaran, 2015). TQM also helps facilitate the reduction of rework, long-range thinking, increased employee participation and teamwork, process re-design, competitive benchmarking, team-based problem-solving, constant measurement of results, and building closer ties with suppliers (Putri et al., 2017; Prajogo \& Sohal 2004; Ross, 1993; Juran, 1992). Given the number of outcomes that TQM can offer and its holistic approach in sustaining the efforts for organizational improvement (Small, Bakry \& Ayyash, 2019), it has thus led to the rationale of choosing TQM as the focus of this study in the area of operations management in manufacturing organizations. TQM in controlled manufacturing industry environments has been studied to a large extent (Small, Bakry \& Ayyash, 2019). Nevertheless, addressing the application of TQM and its impact on production performance and productivity in the manufacturing industry have received less attention (Wong, Kuek \& Ong, 2013).

In this study, TQM measurements represent an assessment of the overall level of people and technical-oriented TQM tools (Davis \& Heineke, 2005). In addition to improving levels of performance, the people and technical-oriented TQM have proven to extract benefits in terms of outcomes derived (Arnheiter \& Maleyeff, 2005). The model proposed here uses TQM dimensions which are derived from prominent studies and documented references (Davis \& Heineke, 2005; Womack \& Jones, 2003). There are six dimensions of people and technical-oriented TQM adapted from several sources (Khang, Arumugam, Chong \& Chan, 2010; Sanders \& Premus, 2002; Porter $\&$ Miller, 1985). These variables are applied to relate to distinctive features of TQM and are therefore incorporated in the present conceptual model as shown in Figure 1. The people-oriented TQM dimensions include: 'Top management Commitment' (TOPMGT), 'Customer Focus' (CFOCUS), and 'Supplier Relations' (SSREL). On the other hand, technical-oriented TQM dimensions include: 'Benchmarking' (BENCH), 'Quality Measurement' (QMEASURE) and 'Process Improvement' (PIMPROVE).

One of the main challenges faced by manufacturing industry in developing countries such as Malaysia has been issues with low productivity (Malaysia Productivity Report, 2017, p.59). Stagnant productivity growth has also been well documented in countries such as United States and Western nations over the last 30 years despite technological advancements (Small, Bakry \& Ayyash, 2019). With the demands of exports, competitiveness, efficiency, quality and timely delivery, addressing the issues of productivity is imperative as high productivity can lead to greater profits for businesses and greater income for individuals. Productivity growth is important because providing more goods and services to consumers translates to higher profits. To provide background for this study, the review of few published resources revealed that top management 
commitment, customer focus and supplier relations are vital factors of TQM in achieving enhanced productivity (Putri et al., 2017; Idris, 2011). Drawing on socio-technical systems theory that refers to the interaction of people and technology in workplace, this study recognizes top management commitment, customer focus and supplier relations as people-oriented TQM. Thus, this paper aims to address productivity issue by highlighting the importance of human interaction as part of peopleoriented TQM dimensions into enhancing productivity, which has been underexplored.

This study also operationalizes production performance as 'production effectiveness' (EFFECT) and 'production efficiency' (EFFICIEN). Production efficiency is concerned with producing goods and services with the optimal combination of inputs to produce maximum output for the minimum cost whereas production effectiveness is when the outcomes of a product meets specified criteria over a period of time (Agus, 2011). In sum, production performance gains came from decreased labour costs, increased throughput and meeting product specifications. However, creating value for customers can be one of the primary goals of an organization, which is often connected to efficiency and effectiveness and primarily affects the output of productivity relations. Any quality management techniques and tools, statistical process control tools or quality information system will be useful in driving efficiency and effectiveness (Chen, 2015). From the perspective of sociotechnical systems theory, this study recognizes benchmarking, quality measurement and process improvement as techniques and tools or technical aspects of TQM in view of optimizing production efficiency and effectiveness.

\subsection{Socio-Technical Systems Theory}

Total Quality Management (TQM) and Socio-Technical Systems Theory (STS) are two work design strategies that have been widely used and recognized to date (Manz \& Stewart,1997). While both approaches advocate some degree of technical proficiency and employee involvement, there is a dearth of research investigating the potential synergies from combining the central elements of the two (Manz \& Stewart, 1997; Cua, McKone \& Schroeder, 2001). As such, this study draws insights from the central elements of TQM and socio-technical systems theory with the aim of incorporating both technical-oriented and people-oriented TQM within the Malaysian manufacturing industry in achieving higher productivity standards. Furthermore, this study seeks to determine the possible ways this method can contribute in improving overall productivity of manufacturing organizations. The socio-technical perspective brings a better understanding to the debates surrounding transitions and changes to systems and is duly applied in this context of this study.

Lloréns, Verdú and Miguel (2003) share the view that TQM elements impact both behavioral and individual's learning processes. In fact, they suggest that TQM elements impact individual processes directly and are mediated by systems and personal factors. Drawing on socio-technical perspective helps in understanding the learning processes arising from the adoption of TQM practices, as well as embracing the synergies of technical efficiency. We are of the view that insights from both TQM and socio-technical theory are important ingredients in gaining a deeper understanding of the various practices that can be adapted to enhance productivity within manufacturing organizations in Malaysia.

Furlan, Vinelli and Dal Pont (2011) established the existence of complementarity between (JIT) and TQM, and showed an enabling role of HRM (Human Resource Management) on such 
complementarity. The researchers interpreted these findings as evidence to suggest that there is a relationship between the TQM variables and the socio-technical aspects of an organization's environment. As such, it can be argued that technical-oriented TQM is significantly related to production performance and this is a result of the synergistic interconnections embedded in the socio-technical approach and TQM. Insights from the TQM literature and the socio-technical perspective contributed to the development of a conceptual framework and hypotheses, which is discussed in the next section.

\subsection{The Conceptual Framework and Hypotheses Development}

\subsubsection{People-oriented TQM and productivity}

People-oriented TQM is operationalized by three important elements of TQM practice which are: 1) employee focus, 2) customer focus; and 3) supplier relations. There are many studies to suggest that these elements represent the 'soft' dimension of TQM (Dubey \& Gunasekaran, 2015; Idris, 2011). Also, numerous literatures are there to suggest that 'soft' aspects of TQM can help build a mindset of embracing organizational quality culture in employees which will help in promoting organizational productivity (Roldan, Leal-Rodriguez \& Leal, 2012; Lenka, Suar \& Mohapatra, 2010). This study interprets 'soft' dimensions as people-oriented TQM as it entails a humancentered approach that can contribute to organizational performance.

Employee focus is an important aspect of quality that can contribute positively towards the success of an organization (Noe, Hollenbeck, Gerhart \& Wright, 2017; Porter \& Kramer, 2019). Many authors have emphasized the importance of changing the overall organizational culture and attitudes of the workforce in order for TQM to be effective (Haffar, Al-Karaghouli, Irani, Djebarni \& Gbadamosi, 2019; Kumar \& Sankaran, 2007; Sohal \& Terziovski, 2000). Welikala and Sohal (2008) found that a lack of ongoing employee involvement at the shop-floor level was the major reason for the non-sustainability of TQM in organizations. This suggests that in order for TQM to be sustainable in organizations, there needs to be a continual focus on employees. This implies that an organization has to pay particular attention to organizational culture, management practices, and organizational structures and systems, which are seen as macro variables in determining the behaviour of employees. Empirically, there are strong evidence to suggest that successful implementation of TQM practices such as teamwork/respect for people, training and education and strong corporate culture have positive effect on employee work related attitudes such as job involvement, job satisfaction, job involvement, organizational commitment and reduced turnover intentions (Baird, Jia \& Reeve, 2011; Karia \& Asaari, 2006; Jabnoun \& Sedrani, 2005; Guimaraes, 1997). As employees are important asset to the organization, it is imperative to focus on employees' development and well-being as employees are the people who are directly involved in the overall processes of the organization and organizational productivity greatly depends on their work attitudes and behaviour (Agus, 2005).

Customer focus is consistently emphasized within organizations as it is imperative that companies realize the importance of meeting the unlimited expectations of its customers. Although customer focus is revered, methods for developing a deeper understanding of the customers' situation are not sufficiently integrated into TQM (Lagrosen, 2001). Cai (2009) suggested that "organizational customer orientation affects customer relationship practices, which subsequently influences production performance and customer satisfaction" (p.369). This will in turn impact 
the organization's production performance, customer satisfaction and financial performance. TQM ensures that customer satisfaction is the number one organizational priority, whereby emphasis is placed on meeting or exceeding customer expectations in every possible transaction (Agus, 2005). Sit, Ooi, Lin and Chong (2009) found that TQM substantially increases customer satisfaction across diverse industrial and cultural settings. It is absolutely vital to include elements of TQM into manufacturing practices as customers are more well informed these days and constantly seek overall value, rather than just being cost effective (Tahir, Mohamad \& Hasan, 2011). As competition intensifies, customer satisfaction is utmost important in developing the business and enhancing growth.

Supplier relations are generally an interactive relationship between parties involved in producing an output that requires an input from another. The rationale for the development of close relationships with suppliers is simple: product quality is best assured by maintaining quality upstream (Agus, 2005; Cai, 2009). Sadikoglu and Olcay (2014) have found that "supplier quality management positively affects operational performance, inventory management performance, innovation performance and overall firm performance" (p.5). Furthermore, Shahin and Dabestani (2011) suggest that the implementation of TQM "requires continuous improvement, not only in products/services quality but also in all operations for creating an organizational quality culture" (p.259). As manufacturers, it is vital to develop a positive relationship with the suppliers as quality begins at the point of supply and translates into benefits to the customers. Nevertheless, such positive coherence is only possible through the empowerment of employees within the organization. Given these theoretical understandings, it is hypothesized that:

\section{$H_{1}$ : People-oriented TQM is significantly related to productivity.}

\subsubsection{Technical-Oriented TQM and Production Performance}

Technical-oriented TQM is operationalized by three important elements of TQM practices in this study and stated as follows: 1) benchmarking, 2) quality measurement, 3) process improvement. Benchmarking refers to the research and the observance of the best competitive practices in view of providing a guideline for rational performance goals and to help set expectations for cost, product reliability and other factors (Agus, 2005; Kaynak, 2003). According to Sajjad and Amjad (2011), benchmarking is an "important strategic tool of total quality management" that focuses on an organization's performance and competitiveness within the business environment. Sajjad and Amjad's (2011) findings revealed that there is a strong positive relationship between benchmarking and overall customer satisfaction, proving that benchmarking helped in improving the quality of the products and services, which led to more satisfied consumers. Quality measurement on the other hand is a goal-oriented measurement with constant performance measurement, often with the use of statistical analysis. The analysis process ensures that all deviations are appropriately considered, measured and responded consistently (Agus, 2005). Process improvement requires everyone in the organization to work towards doing things right the first time. TQM involves preventing errors at the point where work is performed and ultimately every employee and department is responsible for quality (Agus, 2005). Indeed, it is apparent from prior studies that there is a general consensus for a successful implementation of TQM which inevitably leads to organizational wide improvements and overall organizational effectiveness (El-Tohamy \& Raoush, 2015; Kaynak, 2003). 
Cua, McKone and Schroeder (2001) explored the relationships between implementations of TQM (Total Quality Management), JIT (Just in Time), TPM (Total Productive Maintenance) and manufacturing performance. They found that previous studies had explored these concepts in isolation. There was evidence to support the compatibility of these practices. In particular, they found that manufacturing performance is associated with the level of implementation of both people- and technical-oriented practices of the three programs. Based on past studies, it is believed that a joint implementation leads to better results, thereby giving organization the opportunity to reap benefits of benchmarking, quality measurement and process improvement together. Similarly, Furlan, Vinelli and Dal Pont (2011) found the existence of complementarity between JIT and TQM and showed the enabling role of HRM (Human Resource Management) on such complementarity. We interpret these findings as evidence to suggest that benchmarking, quality measurement, and process improvement, among others, would act as key components of technicaloriented TQM.

Quality and performance measurement systems are one of the key components of TQM (Wruck \& Jensen, 1994) and there is an increasing pressure on manufacturing organizations to adopt qualitybased approaches (Agus, 2005). In fact, according to Sinclair and Zairi (1995) "sustainable competitiveness can only be achieved through building robustness into processes and their effective management and control" (p.75), especially in the case of quality measurement and improvement of processes. Sinclair and Zairi (1995) believe that "measurement is the trigger for process management and the achievement of superior competitive standards" (p.75), which is the key to success in any manufacturing organization. It is apparent that the overall organizational culture is particularly significant to the successful implementation of TQM and the overall success of the organization itself. It is this culture that is pivotal in supporting quality improvement and quality measurement work, as well as the flexible implementation of such processes (Shortell, O’Brien, Carman, Foster, Hughes, Boerstler \& O’Connor, 1995). Given these theoretical understandings, it is hypothesized that:

$H_{2}$ : Technical-oriented TQM is significantly related to production performance.

\subsubsection{Production Performance and Productivity}

In order to address the challenges of the ever-evolving global business environment, organizations have started to realize the importance of considering quality as an integral part of their overall strategic business plans (Shahin \& Dabestani, 2011). As investments in quality improvement lead to better performance, TQM becomes a viable competitive strategy. In order to capture the multidimensional nature of performance measures, production performance is manifested by production effectiveness and production efficiency (El-Tohamy \& Raoush, 2015). Production efficiency measures how efficient raw materials are utilized to produce output. Drucker (1963) defines efficiency as the organization's ability to achieve the output(s) considering the minimum input level ("Doing things right"). Production effectiveness measures the percentage of goal achievements in production output. Likewise, Tangen (2005) defines effectiveness as the degree to which desired results are achieved ("Doing the right things"). Outputs and inputs are defined in the total productivity measure as their economic values. Productivity is the ratio of total output to one unit of total input; whereby higher productivity means larger capital gains. When all outputs and inputs are included in the productivity measure it is called total productivity (Rosyada, Mufraini, Suherlan, Harmadi \& Supriyono, 2018). The value of outputs minus the value of inputs 
is a measure of the income generated in a production process. For businesses, productivity growth is important because providing more goods and services to consumers translates to higher profits (Topalovic, 2015). Given this scenario, it is hypothesized that:

$\mathrm{H}_{3}$ : Production performance is significantly related to productivity.

Figure 1: The conceptual model:People-Oriented TQM, Technical-Oriented TQM, Production Performance And Productivity

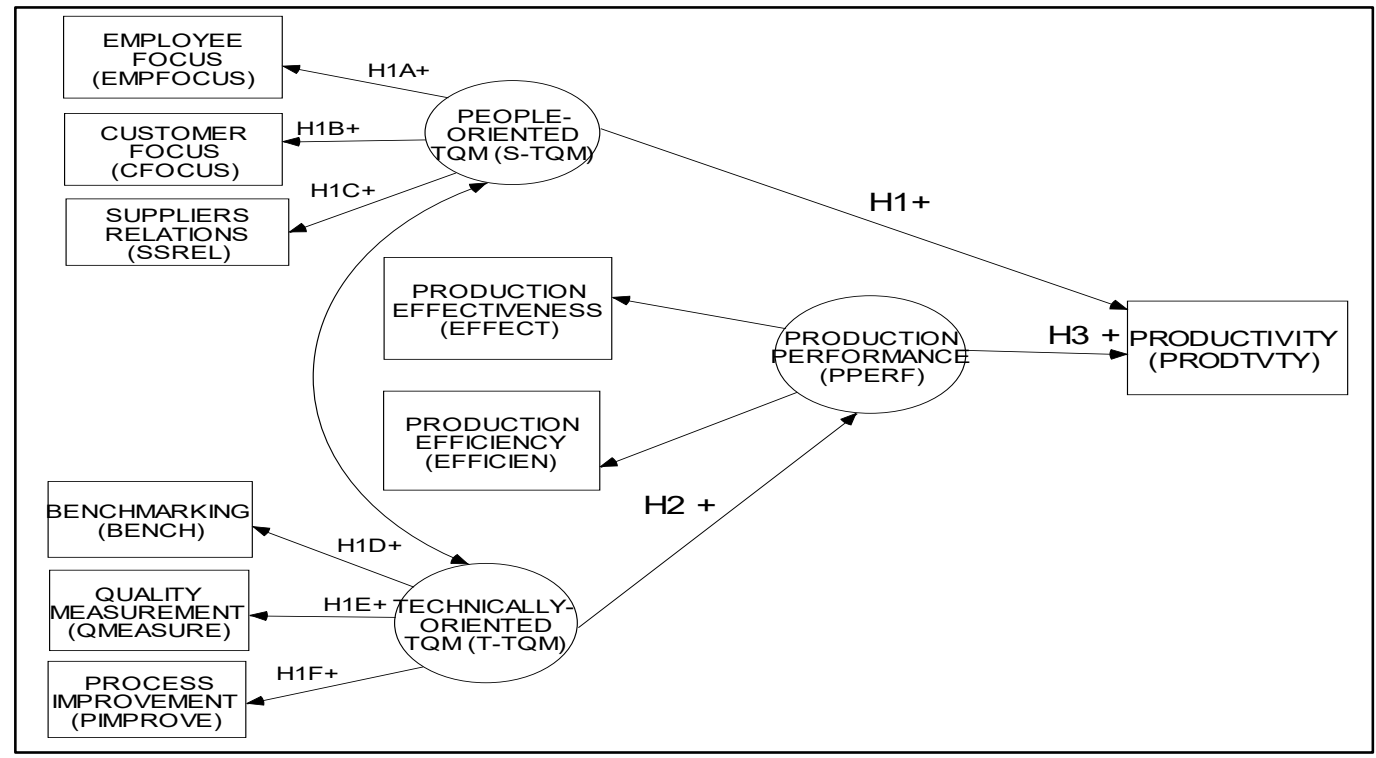

In efforts of investigating the contribution of TQM dimensions towards organizational performance, it is also pertinent to determine the loadings or contributions of each TQM dimension, namely employee focus, customer focus, supplier relations, benchmarking, quality measurement and process improvement. Therefore, six more additional hypotheses are proposed: $H_{1 A}, H_{1 B}, H_{1 C}$ , $H_{1 D}, H_{1 E}$, and $H_{1 F}$ as depicted below:

$H_{1 A}$ : 'Employee focus' has a positive structural loading on people-oriented TQM.

$H_{1 B}$ : 'Customer focus' has a positive structural loading on people-oriented TQM.

$H_{1 C}$ : 'Supplier relations' has a positive structural loading on people-oriented TQM.

$H_{1 D}$ : 'Benchmarking' has a positive structural loading on technical-oriented TQM.

$H_{1 E}$ : 'Quality Measurement' has a positive structural loading on technical-oriented TQM.

$H_{1 F}$ : 'Process improvement' has a positive structural loading on technical-oriented TQM.

The extensive review on literature and the proposed hypothesis has resulted in the development of a conceptual framework as shown in Figure 1. This framework illustrates the linkages between people-oriented TQM, technical-oriented TQM, production performance and productivity. 


\section{METHODOLOGY}

\subsection{Research, Design and Instrument}

This study is quantitative by design and it utilizes a cross-sectional methodology. The research instrument adopted for this study was a structured survey questionnaire, which was designed to assess all dimensions in this study, as outlined in Figure 1. To enable respondents to indicate their answers, a 7-point Likert scale, ranging from 1 (strongly disagree) to 7 (strongly agree), was used in the questionnaire, for example, "over the past three years, performances were high relative to competitors after implementing technical-oriented and people-oriented TQM".

\section{2. $\quad$ Research Sample, Unit of Analysis and Respondent}

The sample unit of analysis in this study was Malaysian manufacturing companies. The sampling frame was derived from the Federation of Malaysian Manufacturers Directory-FMM. Each company was represented by either a senior production or a quality manager, as the respondents of this study. One hundred and sixty nine responses (169) were received and analyzed. Face-to-face interviews with the production managers were carried out to ensure information accuracy and reliability. This also helped us to develop an understanding of the practical aspects of technicaloriented and people-oriented TQM principles. As such, we focused on measuring the managers' perception of TQM and to gain insights into the benefits of implementing TQM on productivity, within the context of Malaysian manufacturers.

\subsection{Reliability and Validity}

Validity and reliability tests were used to select and assess the final items of the independent constructs that were used for statistical testing. Data for the study was mostly generated using multi-scaled responses which were statistically important to conduct the reliability test (Frohlich \& Westbrook, 2001). The internal consistency of each factor was examined using Cronbach alpha. The results indicated that the Cronbach's alpha measures for the main constructs exceeded the threshold point of 0.70, as suggested by Nunnally (1978). Alpha coefficients for TQM and production performance ranged between 0.830 and 0.93 , indicating internal consistency. Nine items for the three constructs were retained for further analyses. Alpha coefficients for people and technical-oriented TQM scales and performance scales ranged between 0.876 and 0.914 after the alpha maximization processes were carried out. Face and content validity were addressed in this study by conducting extensive literature review in determining variables and constructs. The survey instrument was pre-tested with 3 academicians and 5 TQM managers in order to rectify the terms, measurements and structure of the questionnaire. After the first stage of instrument modifications, a pilot test with 30 production or TQM managers was performed and resulted in further changes to the survey instrument. In addition, the confirmatory factor analysis (CFA) or a measurement model using AMOS was employed in examining construct validity of each scale by assessing how well the individual item measured the scale.

The critical variables of TQM practices within this particular study had content validity, because insights were drawn from the literature. Therefore, all the scale items and factors had been evaluated and validated by professionals in the area of operations management or supply chain management. In addition, the draft questionnaire was pre-tested with academicians and a few 
respondents to check its content validity and terminology which were then modified accordingly. On the other hand, convergent validity measures the extent to which a construct is positively correlated with other measures of the same concept of TQM. A bi-variate correlation analysis was computed among the constructs, with the intent of measuring the TQM concept. As these constructs have good correlations among each other, it is suggested that convergent validity is evident. Subsequently, the divergent or discriminant validity was tested, and findings revealed that there were no significant correlations between people and technical-oriented TQM constructs and the associated variables. Thus, the constructs were not measuring other unintended concepts (Frohlich $\&$ Westbrook, 2001). Before creating the final scales, the data was checked for normality and outliers.

In addition, a confirmatory factor analysis (CFA) or a measurement model using AMOS 5 was employed to examine the validity of each construct, by assessing how well the individual item measured the scale. More specifically, a confirmatory factor analysis was employed to detect the uni-dimensionality of each construct. Uni-dimensionality is evidence that a single trait or construct has an underlying set of measures (Hair, Anderson, Tatham \& Black, 1998; Archer \& Lemeshow, 2006). The goodness of fit index (GFI) and comparative fit index (CFI) of the constructs exceeded the 0.90 criterion suggested by Hair et al. (1998), hence, establishing the construct validity (Paul, Pennell \& Lemeshow, 2013). All the items were loaded highly on their corresponding constructs, which supported the independence of the constructs and provided strong empirical evidence of their validity.

\section{RESULTS AND DISCUSSION}

\subsection{The Correlations}

Table 1 exhibits Pearson's correlations between TQM and performance variables. Both production performance dimensions had high correlations with people-oriented TQM dimensions, especially with employee focus and customer focus. Production performance also demonstrated strong correlations with technical-oriented TQM variables, especially with quality measurement. Furthermore, productivity measures also had significant correlations with all technical-oriented and people-oriented TQM variables, especially with supplier relations and process improvements. These findings were consistent with previous studies that proclaimed better organizational transformations as a result of TQM initiatives (Womack, Jones \& Roos, 1990; Agus, 2008).

Table 1: Pearson's correlation between technical-oriented and people-oriented TQM, production performance and productivity

\begin{tabular}{|c|c|c|c|}
\hline TQM & \multicolumn{2}{|c|}{$\begin{array}{c}\text { PRODUCTION } \\
\text { PERFORMANCE }\end{array}$} & PRODUCTIVITY \\
\hline PEOPLE-ORIENTED & PRODUCTION & PRODUCTION & \\
\hline $\begin{array}{l}\text { TQM PRACTICES } \\
\text { (S-TQM) }\end{array}$ & $\begin{array}{c}\text { EFFECTIVENESS } \\
\text { (EFFECTIV) }\end{array}$ & $\begin{array}{c}\text { EFICIENCY } \\
\text { (EFFICIENCY) }\end{array}$ & PRODUCTIVITY \\
\hline 1 Employee Focus & $0.543^{* *}$ & $0.532^{* *}$ & $0.435^{* *}$ \\
\hline 2 Customer Focus & $0.514^{* *}$ & $0.521^{* *}$ & $0.409^{* *}$ \\
\hline
\end{tabular}




\begin{tabular}{|c|c|c|c|}
\hline TQM & \multicolumn{2}{|c|}{$\begin{array}{l}\text { PRODUCTION } \\
\text { PERFORMANCE }\end{array}$} & PRODUCTIVITY \\
\hline 3 Supplier Relations & $0.440^{* *}$ & $0.491^{* *}$ & $0.474^{* *}$ \\
\hline $\begin{array}{l}\text { TECHNICAL- } \\
\text { ORIENTED-ORIENTED } \\
\text { TQM (T-TQM) }\end{array}$ & & & \\
\hline $1 \quad$ Benchmarking & $0.514^{* *}$ & $0.564^{* *}$ & $0.418^{* *}$ \\
\hline 2 Quality Measurement & $0.544^{* *}$ & $0.608^{* *}$ & $0.395^{* *}$ \\
\hline 3 Process Improvement & $0.501^{* *}$ & $0.552^{* *}$ & $0.489^{* *}$ \\
\hline
\end{tabular}

Notes: $1 . \dagger$ if $\mathrm{p}<0.10, *$ if $\mathrm{p}<0.05 ; * *$ if $\mathrm{p}<0.01 ; * * *$ if $\mathrm{p}<0.001$.

2. All correlations are two-tailed

\subsection{The results of the Structural Equation Modelling (SEM)}

Simultaneous linkages through Structural Equation Modelling (SEM) were tested. The use of SEM allows a researcher to determine the relative strength of relationships between variables. The results of the SEM measurement model indicated that the Chi-square value was 42.652 with a p-value of 0.011 (Figure 1). The measurement model fit was evaluated using a number of fit indices such as Goodness of fit index (GFI $=0.947)$, Bentler comparative fit index $(\mathrm{CFI}=0.9985)$, and Normed fit index (NFI $=0.966)$. Since the structural modeling indices were well above the recommended level, the model was considered to be a reasonable fit (Agus, 2011; Agus \& Hajinoor, 2012).

The direct structural effect of people-oriented TQM on productivity (structural effect $=0.280$ ) was considered moderate, suggesting the importance of 'customer focus' followed by 'supplier relations' and 'employee focus' in supporting people-oriented TQM within the Malaysian manufacturing industry. This suggests enough evidence to accept the proposition that peopleoriented TQM has a positive and significant structural effect on productivity ( $H_{1}$ was supported). The direct structural effect of technical-oriented TQM on production performance was high and significant (structural effect $=0.680$ ). Therefore, $\mathrm{H}_{2}$ was also supported. Subsequently, the direct structural effect of production performance on productivity (structural effect $=0.360$ ) was also moderately high and significant and able to support the third hypothesis $\left(\mathrm{H}_{3}\right.$ direct effect was supported). As such, the overall findings also suggested that both technical-oriented and peopleoriented TQM had significant influences on productivity. 
Figure 2: The Structural Equation Model Showing the Linkages Between PeopleOriented TQM, Technical-oriented-Oriented TQM, Production Performance and Productivity.

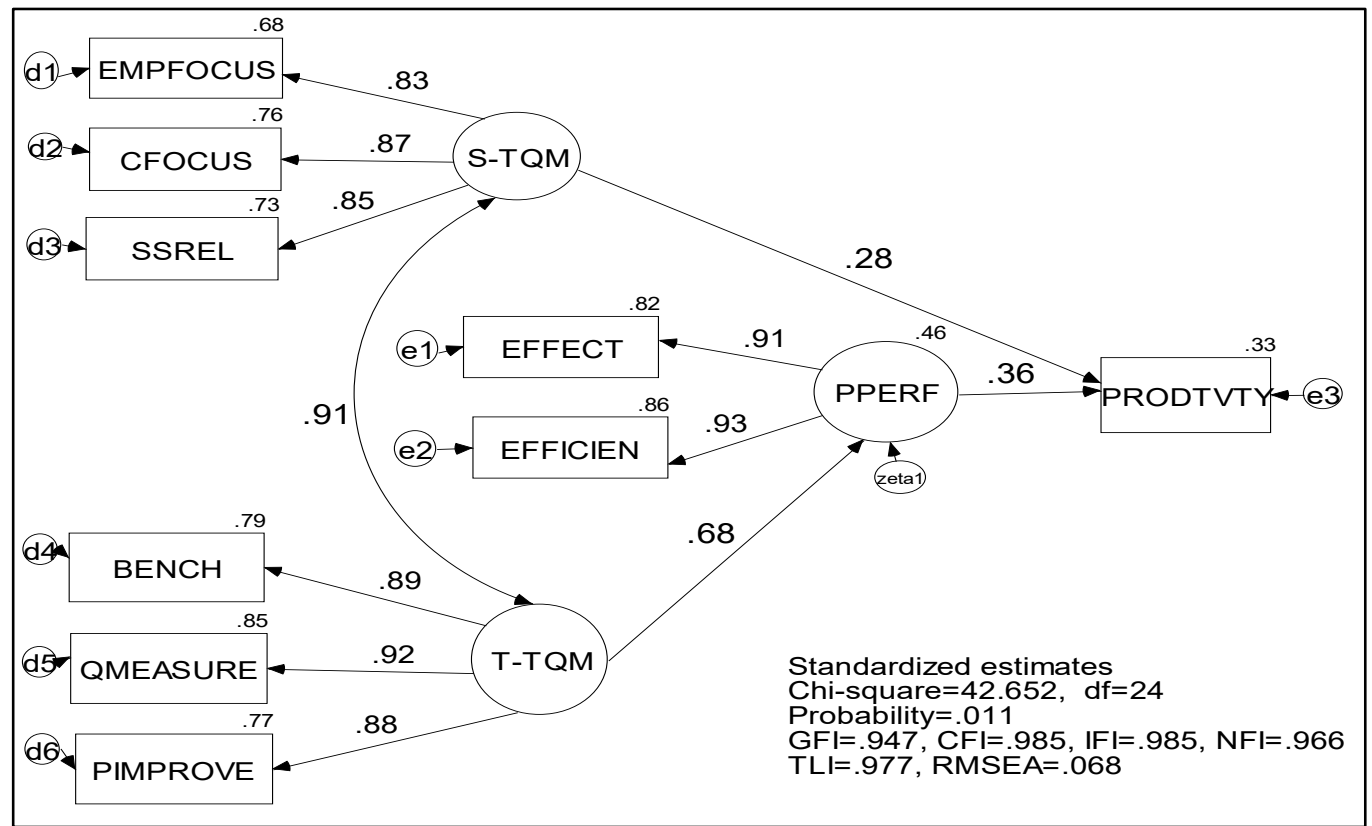

The SEM result also emphasized and indicated the dimensions that manufacturing companies should focus on, especially organizations with limited resources. This is of particular importance especially in emerging economies such as Malaysia where growth in manufacturing companies are relatively marginal and operate within limited budgets. For people-oriented TQM, customer focus (structural loading $=0.87$ ) had the highest contribution to TQM implementation. This was followed by supplier relations (structural loading $=0.85$ ) and employee focus (structural loading $=0.83$ ). Reviewing the structural loadings of each of the technical-oriented TQM dimensions, it was highlighted that quality measurement (structural loading $=0.92$ ) had the highest contribution followed by benchmarking (structural loading $=0.89$ ) and process improvement (structural loading $=0.88$ ) which exhibited significant influences. The SEM results seemed to suggest several recommendations. There is a clear relationship between productivity and customer focus. Therefore, productivity should be defined accordingly with customer benefits and satisfaction in mind. Likewise, the other two people-oriented TQM constructs, namely supplier relations and employee focus also exhibited significant influences. On the other hand, in the technical-oriented TQM constructs, quality measurement was very crucial in influencing and measuring production efficiency and effectiveness. In addition, observing and matching best competitive practices in the market as well as preventing errors at the point where work is performed demonstrated significant impacts on production performance and ultimately productivity (Agus, 2011). 
Table 2: Structural and measurement results of the SEM model

\begin{tabular}{|c|c|c|c|c|c|}
\hline (i)Constructs and indicators & $\begin{array}{c}\text { Std. } \\
\text { Loadings }\end{array}$ & Mean & $\begin{array}{l}\text { Std. } \\
\text { errors }\end{array}$ & $\begin{array}{c}\text { Critical } \\
\text { Ratio }\end{array}$ & Probability \\
\hline \multicolumn{6}{|l|}{ a. People-oriented TQM (S-TQM) } \\
\hline Employee Focus (EMPFOCUS) & 0.828 & 5.574 & 0.077 & 13.212 & 0.000 \\
\hline Customer Focus (CFOCUS) & 0.875 & 5.876 & 0.069 & 14.437 & 0.000 \\
\hline Supplier relations (SSREL) & 0.852 & 5.568 & 0.075 & 13.210 & 0.000 \\
\hline \multicolumn{6}{|l|}{ b. Technical-Oriented TQM (T-TQM) } \\
\hline Benchmarking (BENCH) & 0.887 & 5.580 & 0.052 & 18.135 & 0.000 \\
\hline $\begin{array}{l}\text { Quality Measurement } \\
\text { (QMEASURE) }\end{array}$ & 0.922 & 5.651 & 0.053 & 17.697 & 0.000 \\
\hline $\begin{array}{l}\text { Process Improvement } \\
\text { (PIMPROVE) }\end{array}$ & 0.878 & 5.704 & 0.061 & 17.690 & 0.000 \\
\hline \multicolumn{6}{|l|}{ c. Production Performance (PPERF) } \\
\hline $\begin{array}{l}\text { Production Effectiveness } \\
\text { (Effective) }\end{array}$ & 0.907 & 5.308 & 0.067 & 14.718 & 0.000 \\
\hline Production Efficiency (Efficien) & 0.928 & 5.343 & 0.068 & 14.710 & 0.000 \\
\hline \multicolumn{6}{|l|}{ d. Productivity (PRODTVTY) } \\
\hline $\begin{array}{l}\text { (ii) Exogenous/endogenous Path } \\
\text { a. S-TQM } \rightarrow \text { PRODTVTY }\left(H_{1} \text { is }\right. \\
\text { supported) }\end{array}$ & 0.276 & - & 0.105 & 3.025 & 0.002 \\
\hline $\begin{array}{l}\text { b. T-TQM } \rightarrow \text { PPERF }\left(\mathrm{H}_{2} \text { is }\right. \\
\text { supported) }\end{array}$ & 0.678 & & 0.077 & 9.335 & 0.000 \\
\hline $\begin{array}{l}\text { c. PPERF } \rightarrow \text { PRODTVTY ( } H_{3} \text { is } \\
\text { supported) }\end{array}$ & 0.359 & - & 0.083 & 3.951 & 0.000 \\
\hline
\end{tabular}

\section{CONCLUSION AND IMPLICATIONS}

This study explores and contributes further knowledge towards the importance of relationships between technical-oriented and people-oriented TQM, production performance and productivity. To meet the increasing demands of high-quality goods, manufacturing companies in Malaysia, regardless of size, must continually improve their efforts with the aim of enhancing operational aspects. The pursuit of these improvements is not only to cater to demanding customers, but also driven by the needs for organizational excellence to survive in a competitive global business environment. Results of the Pearson's correlations and SEM model extracted from 169 manufacturing companies support the following conclusions: 1) TQM dimensions have significant correlations with production performance and productivity; 2) people-oriented TQM has a positive and direct effect on productivity; 3) technical-oriented TQM has a positive and direct effect on production performance and; 4) production performance has a positive direct effect on productivity.

Manufacturing companies continuously strive in enhancing productivity through proper quality programs and methods for reasons that have been mentioned above. As such, TQM appears to be one of the best ways to improve performance. Parasuraman (2010) emphasizes on the importance of consistently analyzing productivity to boost capability within the manufacturing sector. 
Productivity has been a core valuation factor when determining the strength of a manufacturing company. It is also important to analyze productivity because it encourages organizations to produce high quality and value-added products from quality input (supplier relations) that are highly sought by customers (customer focus), which is a critical factor for the survival of the company. Also, not forgetting the ever-changing landscape of consumer demand whereby products are expected to be of high quality due to the nature of availability and comparability. Therefore, the value of productivity was measured based on effectiveness and efficiency in order to achieve accurate and valuable results (Kumar \& Gulati, 2009). However, a firm may be efficient in using the resources (inputs), but not effective (Kumar \& Gulati, 2009). We contend that if production increases without due regards to the quality of the processes, there will be, in all likelihood, an increased share of low quality and defective products and services, leading to poor performance by manufacturing companies in Malaysia. Hence, there is a need to embrace TQM dimensions as this helps to enhance the performance of manufacturing organizations, as illustrated by the findings of this study. The competitive nature of modern-day business forces a firm to continuously improve business performance. Malaysian manufacturers should adopt TQM dimensions in pursuing excellence from both perspectives of enhancing productivity and gaining a competitive advantage by providing quality products. Manufacturers in developed countries have reaped the benefits of practicing TQM dimensions in their organizations (Denan, Ismail \& Ramayah, 2012). However, using the socio-technical perspective, this study incorporates people-oriented aspect into the TQM variables that is believed to strengthen the need and outcome of practice.

It is also important to emphasize that effective supplier quality management is facilitated by longterm, cooperative relationships, by engaging as few suppliers as possible, in view of obtaining quality materials and/or services. Maintaining a small number of suppliers improves product quality and productivity of buyers by encouraging enhanced supplier commitment to product design and quality. Quality creates not only a price/value advantage over competitors but also enables the firm to charge a higher per/unit sale price through differentiation. As such, Malaysian manufacturers will gain added advantage in the future by being recognized as producers of quality products which are on par with western counterparts.

On the other hand, technical-oriented TQM plays a crucial role in enhancing performances of manufacturers. Continuous improvement is a change that focuses on increasing the effectiveness and/or efficiency of an organization to fulfil its policy and objectives. It is not limited to only quality initiatives. Improvement in business strategy, business results, customer, employee and supplier relationships can be subjects to continual improvement equally. There are three types of improvements manufacturers could pursue in enhancing competitiveness. Continuous improvement is gradual never-ending change, whereas continual improvement is an incremental change. Both types of improvements are what the Japanese call as Kaizen. Breakthroughs are improvements, but in one giant leap - as a change. However, the method of achievement is the same, yet breakthroughs tend to arise out of chance discoveries and could take years, before achieving something significant. In addition, benchmarking is used to determine the best, in terms of a specific range of capabilities and to identify world-class performance levels. Benchmarking is also widely used to determine the drivers of superior performance within competing organizations, to quantify gaps between the benchmarker's performance and what is determined as world-class performance standards. By doing so, manufacturers are able to identify best practices in key business processes, share knowledge of best practices, and build foundations for performance improvements. With the growing awareness that quality of final products and services is a strategic 
competitive variable, companies have recognized that the concept of high quality must be applied to process improvements to generate quality and cost-effective products. The Malaysian manufacturing sector will remain a vital component of the economy, as it is one of the largest contributors to the country's economic growth as measured by its contribution to the gross domestic product (GDP). As such, the issue of the competitive advantage of domestic manufacturers is high on the national economic agenda (Ismail, Domil \& Isa, 2014). By implementing TQM to enhance productivity measures, Malaysian manufacturers will gain competitive advantage by producing quality products/services while creating value added services that could distinguish us from competitors outside Malaysia.

\section{IMPLICATIONS AND LIMITATIONS}

The managerial contribution of this study highlights to managers that evaluating accurate productivity levels must be a directive rather than a mere procedure for production managers and policy makers, which enable manufacturing companies to redesign and revise their objectives and strategies based on the real values of enhancing competitive advantages. Therefore, by understanding the predicament of the environment more precisely, managers could reduce wastages and enhance cost saving measures which will allow their organizations to allocate resources more efficiently. Future studies could evaluate productivity and use determinants that are related to an organization's line of work. In other words, determinants of productivity, performance and other antecedents should be embraced to ensure that this research agenda is consistent with the changes that are ever evolving in business environment.

\section{REFERENCES}

Agus, A. (2005). The structural linkages between TQM, product quality performance and business performance: Preliminary empirical study in electronics companies. Singapore Management Review, 27(1), 87-105.

Agus, A. (2008). Quality management profitability linkage: Does the length of QM adoption act as the moderating variable? International Journal of Management Studies, 15(1), 1-23.

Agus, A. (2011). The structural influence of supply chain management on product quality and business performance. International Journal of Trade, Economics and Finance (IJTEF), 2(4), 269-275.

Agus, A., \& Hajinoor, M. (2012). Lean production supply chain management as driver towards enhancing product quality and business performance: Case study of manufacturing companies in Malaysia. International Journal of Quality and Reliability, 29(1), 92-121.

Archer, K., \& Lemeshow, S. (2006). Goodness-of-fit test for a logistic regression model fitted using survey sample data. State Journal, 6(1), 97-105.

Arnheiter, E. D., \& Maleyeff, J. (2005). The integration of lean management and Six Sigma. The TQM Magazine, 17(1), 5-18.

Baird, K., Jia, H., \& Reeve, R. (2011). The relationships between organizational culture, total quality management practices and operational performance. International Journal of Operations \& Production Management, 31(7), 789-814. 
Cai, S. (2009). The importance of customer focus for organizational performance: A study of Chinese companies. International Journal of Quality \& Reliability Management, 26(4), 369-379.

Chen, Z. (2015). The relationships among JIT, TQM and production operations performance. Business Process Management Journal, 21(5), 1015-1039.

Cua, K., McKone, K., \& Schroeder, R. (2001). Relationships between implementation of TQM, JIT, and TPM and manufacturing performance. Journal of Operations Management, 19(6), 675-694.

Davis, M., \& Heineke, J. (2005). Operations management: Integrating Manufacturing and Services. 5th ed. New York: McGraw-Hill/Irwin.

Denan, Z., Ismail, N., \& Ramayah, T. (2012). Owners' prior knowledge and performance: The mediation effect of knowledge absorptive capacity amongst SMEs. 2012 IEEE International Technology Management Conference, 351-359.

Drucker, P. (1963). Managing for business effectiveness. Harvard Business Review, 41(1), 53-60.

Dubey, R., \& Gunasekaran, A. (2015). Exploring soft TQM dimensions and their impact on firm performance: some exploratory empirical results. International Journal of Production Research, 53(2), 371-382.

El-Tohamy, A., \& Raoush, A. (2015). The impact of applying total quality management principles on the overall hospital effectiveness: An empirical study on the HCAC accredited governmental hospitals in Jordan. European Scientific Journal, 11(10), 63-72.

Frohlich, M., \& Westbrook, R. (2001). Arcs of integration: An international study of supply chain strategies. Journal of Operations Management, 19(2), 185-200.

Furlan, A., Vinelli, A., \& Dal Pont, G. (2011). Complementarity and lean manufacturing bundles: an empirical analysis. International Journal of Operations and Production Management, 31(8), 835-850.

Guimaraes, T. (1997). Assessing employee turnover intentions before/after TQM. Journal of Quality and Reliability, 14(1), 46-63.

Haffar, M., Al-Karaghouli, W., Irani, Z., Djebarni, R., \& Gbadamosi, G. (2019). The influence of individual readiness for change dimensions on quality management implementation in Algerian manufacturing organizations. International Journal of Production Economics, 207, 247-260.

Hair, J., Anderson, R., Tatham, R., \& Black, W. (1998). Multivariate data analysis. Prentice-Hall, Englewood Cliff, New Jersey.

Idris, F. (2011). Total Quality Management (TQM) and Sustainable company performances: Examining the relationship in Malaysian. International Journal of Business and Society, 12(1), 31-52.

Ilkay, M. S., \& Aslan, E. (2012). The effect of the ISO 9001 quality management system on the performance of SMEs. International Journal of Quality \& Reliability Management, 29(7), 753-778.

Ismail, M. D., Domil, A. K. A., \& Isa, A. M. (2014). Managerial competence, relationship quality and competitive advantage among SME exporters. Procedia-Social and Behavioral Sciences, 115, 138-146.

Jabnoun, N., \& Sedrani, K. (2005). TQM, culture, and performance in UAE manufacturing firms. The Quality Management Journal, 12(4), 8-23.

Juran, J. (1992). Juran on quality by design: The new steps for planning quality into goods and services. Free Press: Macmillan, Inc., New York. 
Kang, N., Zhao, C., Li, J., \& Horst, J.A., (2016). A hierarchical structure of key performance indicators for operation management and continuous improvement in production systems. International Journal of Production Research, 54(21), 6333-6350.

Karia, N., \& Asaari, M. (2006). The effects of total quality management practices on employees' work-related attitudes. The TQM Journal, 18(1), 30-43.

Kaynak, H. (2003). The relationship between total quality management practices and their effects on firm performance. Journal of Operations Management, 21(4), 405-435.

Khademfar, M., \& Amiri, S. A. (2013). The relationship between ethical leadership and organizational performance (Small Review on Malaysian Studies). International Journal of Business and Social Science, 4(1), 114-120.

Khang, T. S., Arumugam, V., Chong, A. Y. L., \& Chan, F. T. S. (2010). Relationship between supply chain management practices and organization performance: A case study in the Malaysian service industry. International Journal of Modelling in Operations Management, 1(1), 84-106.

Kumar, M., \& Sankaran, S. (2007). Indian culture and the culture of TQM: A comparison. The TQM Magazine, 19, 176-188.

Kumar, S., \& Gulati, R. (2009). Measuring efficiency, effectiveness and performance of Indian public sector banks. International Journal of Productivity and Performance Management, $59,51-74$.

Lagrosen, S. (2001). Strengthening the weakest link of TQM-from customer focus to customer understanding. The TQM Magazine, 13(1), 348-354.

Lenka, U., Suar, D., \& Mohapatra, P. (2010). Soft and hard aspects of quality management practices influence service quality and customer satisfaction in manufacturing-oriented services. Global Business Review, 11(1), 79-101.

Lloréns, M., F., Verdú., J., A., \& Miguel M. F. L. (2003). Factors affecting the relationship between total quality management and organizational performance. International Journal of Quality \& Reliability Management, 20(2), 189-209.

Malaysia. Productivity Report 2016/2017. (2017). Productivity Performance of the Manufacturing Sector. Available at: http://www.mpc.gov.my/wp-content/uploads/2017/05/ProductivityReport-2017.pdf (Accessed: 07 July 2019).

Manz, C., \& Stewart, G. (1997). Attaining flexible stability by integrating total quality management and socio-technical systems theory. Organization Science, 8(1), 59-70.

Neely, A., Gregory, M., \& Platts, K. (2005). Performance measurement system design: A literature review and research agenda. International Journal of Operations \& Production Management, 25, 1228-1263.

Noe, R. A., Hollenbeck, J. R., Gerhart, B., \& Wright, P. M. (2017). Human resource management: Gaining a competitive advantage. New York, NY: McGraw-Hill Education.

Nunnally, J. C. (1978). Psychometric Theory. New York: McGraw-Hill.

Ooi, K. B. (2015). TQM practices and knowledge management: A multi-group analysis of constructs and structural invariance between the manufacturing and service sectors. Total Quality Management and Business Excellence, 26(11-12), 1131-1145.

Parasuraman, A. (2010). Service productivity, quality and innovation: Implications for servicedesign practice and research. International Journal of Quality and Service Sciences, 2, 277-286.

Paul, P., Pennell, M., \& Lemeshow, S. (2013). Standardizing the power of the Hosmer-Lemeshow goodness of fit test in large data sets. Statistics in Medicine, 32(1), 67-80. 
Porter, M. E., \& Millar, V. E. (1985). How information gives you competitive advantage. Harvard Business Review, 63(4), 149-160.

Porter, M. E., \& Kramer, M. R. (2019). Creating shared value. In Managing sustainable business (pp. 323-346). Springer, Dordrecht.

Prajogo, D. I., \& Sohal, A. S. (2004). The relationship between organization strategy, total quality management (TQM), and organization performance - The mediating role of TQM. European Journal of Operation Research, 168, 35 - 50.

Putri, N. T., Mohd Yusof, S., Hasan, A., \& Darma, H. S. (2017). A structural equation model for evaluating the relationship between total quality management and employees' productivity. International Journal of Quality \& Reliability Management, 34(8), 1138 1151.

Roldan, J. L., Leal-Rodriguez, A. L., \& Leal, A. G. (2012). The influence of organizational culture on the Total Quality Management Programme Performance. Investigaciones Europeas de Direccion y Economia de la Empresa, 18(3), 183-189.

Ross, J. (1993). Total Quality Management: Text, Cases and Reading. St. Lucie Press, Delray Beach. Fl.

Rosyada, D., Mufraini, M. A., Suherlan, A., Harmadi, H., \& Supriyono, S. (2018). Promoting Islamic values to encourage labour performance and productivity: Evidence from some Indonesian industries. International Journal of Business and Society, 19(S4), 591-604.

Sadikoglu, E., \& Olcay, H. (2014). The effects of total quality management on performance and the reasons of and the barriers to TQM practices in Turkey. Advances in Decision Sciences, 14, 1-17.

Saieed, Z. (2018, October 31). PM unveils four-pronged strategy to boost manufacturing. The Star Online. Retrieved from https://www.thestar.com.my/business/businessnews/2018/10/31/pm-unveils-four-pronged-strategy-to-boost-manufacturing/

Sajjad, F., \& Amjad, S. (2011). Assessment of Total Quality Management Practices and Organizational Development. Mediterranean Journal of Social Sciences, 2(2), 321-330.

Sanders, N. R., \& Premus, R. (2002). IT applications in supply chain organizations: A link between competitive priorities and organizational benefits. Journal of Business Logistics, 23(1), 65-84.

Setó-Pamies, D. (2012). Customer loyalty to service providers: Examining the role of service quality, customer satisfaction and trust. Total Quality Management \& Business Excellence, 23(12), 1257-1271.

Shahin, A., \& Dabestani, B. (2011). A feasibility study of the implementation of total quality management based on factor. Journal of Industrial Engineering and Management, 4(2), 258-280.

Shortell, S. M., O'Brien, J. L., Carman, J. M., Foster, R. W., Hughes, E. F., Boerstler, H., \& O'Connor, E. J. (1995). Assessing the impact of continuous quality improvement/total quality management: Concept versus implementation. Health Services Research, 30(2), 377-401.

Sinclair, D., \& Zairi, M. (1995). Effective process management through performance measurement: Part 1-Applications of total quality-based performance measurement. Business Process Re-engineering \& Management Journal, 1(1), 75-88.

Sinha, N., Garg, A. K., \& Dhall, N. (2016). Effect of TQM principles on performance of Indian SMEs: the case of automotive supply chain. The TQM Journal, 28(3), 338359. 
Sit, W., Ooi, K., Lin, B., \& Chong, Y. L. A. (2009). TQM and customer satisfaction in Malaysia's service sector. Industrial Management \& Data Systems, 109(7), 957-975.

Small, E.P., Bakry, I., \& Ayyash, L.A. (2019). Evaluating the effect of TQM on MEP construction productivity and project delivery in Dubai. International Journal of Construction Management, 1-15.

Sohal, A., \& Terziovski, M. (2000). TQM in Australian manufacturing: Factors critical to success. International Journal of Quality \& Reliability Management, 17, 158-168.

Song, H., Zhao, C., \& Zeng, J. (2017). Can environmental management improve financial performance: An empirical study of A-shares listed companies in China. Journal of cleaner production, 141, 1051-1056.

Tahir, P.R., Mohamad, M.R., \& Hasan, D.B. (2011). A short review of factors leading to success of Small Medium Enterprises. Interdisciplinary Journal of Contemporary Research on Business, 519-529.

Tangen, S. (2005). Demystifying productivity and performance. International Journal of Productivity and Performance Management, 54(1), 34-46.

Topalovic, S. (2015). The implementation of total quality management in order to improve production performance and enhancing the level of customer satisfaction. Procedia Technology, 19, 1016-1022.

Welikala, D., \& Sohal, A. (2008). Total quality management and employees' involvement: A case study of an Australian organization. Total Quality Management, 19(6), 627-642.

Womack, J. P., \& Jones, D. T. (2003). Lean thinking: Banish waste and create wealth in your corporation. New York: Free Press.

Womack, J., Jones, D., \& Roos, D. (1990). The Machine That Changed the World: The Story of Lean Production, Toyota's Secret Weapon in the Global Car Wars That Is Now Revolutionizing World Industry. Free Press, New York.

Wong, K. L., Kuek, T. Y., \& Ong, S. F. (2013). Strategic Planning and Business Performance: A Study of SMEs in Malaysia Proceedings of 3rd Asia-Pacific Business Research Conference. 3rd Asia-Pacific Business Research Conference 25 - 26 February 2013, Kuala Lumpur, Malaysia.

Wruck, K., \& Jensen, M. (1994). Science, specific knowledge, and total quality management. Journal of Accounting and Economics, 18(3), 247-287. 